\title{
B-Type Natriuretic Peptide: A Predictor for Mortality, Intensive Care Unit Length of Stay, and Hospital Length of Stay in Patients With Resolving Sepsis
}

\author{
Harsimar Singha, Daryl Ramaib, d, Harshil Patel ${ }^{\mathrm{a}}$, Marina Iskandira ${ }^{\mathrm{a}}$, Sarina Sachdev ${ }^{\mathrm{a}}$, \\ Rabjot Raib ${ }^{\mathrm{b}}$ Jay Patolia ${ }^{\mathrm{b}}$, Getaw Worku Hassen ${ }^{\mathrm{c}}$
}

\begin{abstract}
Background: B-type natriuretic peptide (BNP) is a hormone secreted by cardiomyocytes in response to myocardial ischemia, increased ventricular wall tension, and overload. BNP is utilized as a diagnostic and prognostic marker in congested heart failure (CHF). Its prognostic value in sepsis is unknown. The aim of this study is to determine if BNP correlates with increased in-hospital mortality for septic patients.

Methods: This was a retrospective study of 505 patients admitted for sepsis or severe sepsis or septic shock during the period of January 2013 and August 2014. Patients that received > 3 L of intravenous fluids on presentation were included. Intensive care unit length of stay (ICULOS), hospital length of stay (HLOS) and in-hospital mortality were measured. Mean BNP level was calculated and compared to ICULOS and HLOS and in-hospital mortality. Controlled variables included ejection fraction (measured by echocardiogram within 6 months of presentation), glomerular filtration rate (calculated by Cockroft-Gault equation), patient demographics, and lactic acid trends. Exclusion criteria were no echocardiogram within 6 months of admission, no BNP levels on admission, and no repeat lactate or rising lactate levels within $24 \mathrm{~h}$ to indicate worsening sepsis.
\end{abstract}

Results: Patients' mean BNP with in-hospital mortality was 908 $\mathrm{pg} / \mathrm{mL}$ as compared to mean BNP of $678 \mathrm{pg} / \mathrm{mL}$ in survivors. T-test comparisons were statistically significant $(\mathrm{P}=0.0375)$. The KaplanMeier curve for BNP as a predictor for in-hospital mortality showed that for the first 25 days, patients with BNP higher than $500 \mathrm{pg} / \mathrm{mL}$ had a higher mortality than patients with BNP lower than $500 \mathrm{pg} / \mathrm{mL}$. When comparing HLOS, there is a statistically significant correlation

Manuscript submitted October 28, 2017, accepted November 10, 2017

aDepartment of Medicine, New York University School of Medicine, 150 55th St, Brooklyn, NY 11220, USA

bDepartment of Anatomical Sciences, St George's University School of Medicine, True Blue, Grenada, WI

'Department of Emergency, New York University School of Medicine, 150 55th St, Brooklyn, NY 11220, USA

${ }^{\mathrm{d} C}$ Corresponding Author: Daryl Ramai, Department of Anatomical Sciences, St George's University School of Medicine, True Blue, Grenada, WI.

Email: dramai@sgu.edu

doi: https://doi.org/10.14740/cr605w
$(\mathrm{P}=0.0046)$. A similar scatter plot was prepared for ICULOS which showed there was a weak positive correlation $(r=0.199)$.

Conclusion: Septic patients with in-hospital mortality had an average $\mathrm{BNP}$ of $908 \mathrm{pg} / \mathrm{mL}$ and statistically significant higher HLOS.

Keywords: Brain natriuretic peptide; Diagnostic markers; Sepsis; Mortality; Intensive care unit

\section{Introduction}

B-type natriuretic peptide (BNP) is a hormone secreted into the blood by cardiomyocytes, largely in response to myocardial ischemia, increased ventricular wall tension, and pressure overload [1]. BNP affects salt and water homeostasis, protecting the heart from volume overload [2]. Specifically, it induces vaso-relaxation, diuresis, and natriuresis [3]. Due to these mechanisms, BNP is widely utilized as a diagnostic and prognostic marker in congested heart failure (CHF) [4], and is regarded as a strong predictor of mortality and adverse outcomes in patients with acute coronary syndrome [5], pulmonary embolism [6], and stable coronary artery disease [7].

BNP and N-terminal pro-BNP (NT-proBNP) have been shown to have diagnostic, therapeutic, and prognostic utility in patients with normal renal function. Systemic BNP levels can be influenced by the degree of renal function, rendering BNP and NT-proBNP of limited functionality during renal disease [8]. However, it should be noted that these markers remain reliable predictors of mortality in dialysis patients, independent of dialysis modality and degree of fluid volume control [9].

Sepsis is one of the leading causes of mortality in intensive care units (ICUs) [10]. It occurs when an infection leads to widespread immune activation, causing diffuse circulatory abnormalities and multiple organ failures [11-13]. It is a complex pathophysiological process and shows high immune variability in patient populations of different ethnicities and gender [14]. Accordingly, several studies have investigated the implementation of a combination of various biomarkers and APACHE-II/SOFA scores in order to achieve better sensitivity and specificity where single biomarkers have failed to produce [15-21]. Factors that attribute to a rise in BNP levels in sepsis include pro-inflammatory cytokine over-secretion [22], 
proceeding systolic and diastolic biventricular abnormalities [23], altered BNP clearance [24], renal failure [25], and sepsisassociated acute lung injury or acute respiratory distress syndrome (ARDS) [26].

The aim of this study is to determine whether a high initial BNP level predicts higher mortality and morbidity in septic patients while controlling for ejection fraction (EF), glomerular filtration rate (GFR), and fluids administered for resolution of sepsis within the first $24 \mathrm{~h}$.

\section{Materials and Methods}

Patients were selected based on the Surviving Sepsis Campaign: International Guidelines for Management of Severe Sepsis and Septic Shock: 2012. Patients were pooled under SIRS criteria, sepsis, severe sepsis or septic shock.

\section{Study population}

The study was a retrospective chart review of patients admitted under International Classification of Disease (ICD) code 9 for sepsis, severe sepsis, and septic shock between the dates of January 1, 2013 and August 31, 2014. Patients were diagnosed with sepsis by the ED physician during admission or were diagnosed by the admitting physician in the ED or medical floors. The amount of fluid administered was calculated for the first $24 \mathrm{~h}$ after the diagnosis of sepsis. The fluid values included the amount of fluid administered within antibiotics, bolus and maintenance intravenous (IV) fluids, and any other IV medications. Patients that received more than $3 \mathrm{~L}$ of fluid within $24 \mathrm{~h}$ after being diagnosed with sepsis were included in our study. The value of $3 \mathrm{~L}$ fluids was established based on the $30 \mathrm{cc} / \mathrm{kg}$ model for fluid resuscitation in sepsis as this would account for most patients. To ensure that sepsis was resolving, we included lactate trends of within $24 \mathrm{~h}$ and a final lactate. All 505 patients included in the study had decreasing lactate within $24 \mathrm{~h}$. Patients with rising lactate levels indicating worsening sepsis were excluded from this study. EF was also recorded for patients in the last 6 months of presentation or during their admission. Low EF was defined as less than $45 \%$ and normal $\mathrm{EF}$ was defined as more than or equal to $45 \%$. GFR was calculated by Cockroft-Gault equation based on the initial creatinine and BUN along with weight on presentation [27]. The normal BNP based on our laboratory standards ranged from 2 to $100 \mathrm{pg} / \mathrm{mL}$. Patients were excluded if there was no recent echocardiogram within 6 months, no BNP drawn on admission, or signs indicating worsening sepsis, i.e. no repeat lactate level or rising lactate levels.

\section{Statistical analysis}

Patients' ICU length of stay (ICULOS), hospital length of stay (HLOS), and in-hospital mortality were recorded. BNP was measured in 505 patients. Eighteen patients were excluded because of incomplete data, leaving a final study population of
Table 1. Characteristics of Study Demographics

\begin{tabular}{|c|c|c|c|c|}
\hline & $\mathbf{n}$ & $\%$ & In-hospital death & P-value \\
\hline \multicolumn{5}{|l|}{ Gender } \\
\hline $\mathrm{F}$ & 275 & 56.5 & 0.251 & 0.731 \\
\hline M & 212 & 43.5 & 0.269 & \\
\hline \multicolumn{5}{|l|}{$\mathrm{EF}$} \\
\hline$<45 \%$ & 104 & 21.4 & 0.308 & 0.246 \\
\hline$>45 \%$ & 383 & 78.6 & 0.245 & \\
\hline \multicolumn{5}{|l|}{ IVF } \\
\hline$>3 \mathrm{~L}$ & 113 & 31.7 & 0.372 & 0.001 \\
\hline$<3 \mathrm{~L}$ & 243 & 68.3 & 0.198 & \\
\hline \multicolumn{5}{|l|}{ BNP } \\
\hline$>500$ & 194 & 41.5 & 0.278 & 0.333 \\
\hline$<500$ & 273 & 58.5 & 0.234 & \\
\hline \multicolumn{5}{|l|}{ Intubation } \\
\hline Yes & 282 & 57.8 & 0.139 & $<0.001$ \\
\hline No & 206 & 42.2 & 0.422 & \\
\hline \multicolumn{5}{|c|}{ Signs of CHF } \\
\hline Yes & 229 & 54.21 & 0.279 & $<0.59$ \\
\hline No & 191 & 45.5 & 0.251 & \\
\hline \multicolumn{5}{|l|}{ On Lasix } \\
\hline Yes & 254 & 57.92 & 0.31 & 0.025 \\
\hline No & 178 & 42.08 & 0.208 & \\
\hline \multicolumn{5}{|c|}{ In-hospital death } \\
\hline Yes & 126 & 25.87 & & $<0.001$ \\
\hline No & 361 & 74.13 & & \\
\hline
\end{tabular}

EF: ejection fraction; IVF: intravenous fluids; CHF: congestive heart failure.

487 patients. One hundred and ninety-four patients had BNP concentrations $>500 \mathrm{pg} / \mathrm{mL}$. The present cohort had fewer males $(43.5 \%$ vs. $56.5 \%)$, more signs of congested heart failure (CHF) $(54.2 \%$ vs. $45.5 \%)$, and $25 \%$ in-hospital death (P $<0.001)$. Furthermore, fewer patients had an EF of less than $45 \%$ ( $21.4 \%$ vs. $78.6 \%$; $\mathrm{P}=0.246)$. Data analyses were conducted by comparing in-hospital mortality, HLOS and ICULOS for patients with BNP greater than 500 and less than 500 . $\mathrm{BNP}$ level of less than 100 has a high negative predictive value $(90 \%)$, while the BNP range of $100-500$ is referred as the "gray-zone" and has been debated for being diagnostically ambiguous as a marker for assessing clinical outcomes in patients with CHF $[28,29]$. We therefore chose a BNP of 500 as our cut-off, and compared the average BNP levels of patients with mortality versus patients who survived. We calculated the relative risk (RR) of in-hospital death for patients with high $\mathrm{BNP}(>500)$ compared to low BNP $(\leq 500)$ using robust Poisson regression model, and calculated Kaplan-Meier curves to descriptively explore differences in mortality. On visual analysis of survival curves by low vs. high BNP, the data did not meet the proportional hazards assumption, and thus no formal 
hypothesis testing was conducted to compare mortality rates. Instead, we calculated relative risk for mortality using robust Poisson regression. To calculate the ratio of lengths of stay in the hospital and in the ICU between patients with high vs. low $\mathrm{BNP}$, we used negative binomial regression. All regression analyses were adjusted for GFR and EF, as BNP levels can be confounded by renal failure and severe heart failure. Results were considered statistically significant if two-sided $P$ values were less than 0.05 . All analyses were conducted using R Statistics version 3.3 .

\section{Results}

As an overview, the median BNP level for our selected patient population ( $\mathrm{n}=505 ; 56 \% \mathrm{~F}, 44 \% \mathrm{M}$ ) was $410 \mathrm{pg} / \mathrm{mL}$ (Table 1). Median HLOS and ICULOS were 11 and 3 days, respectively. These patients showed decreasing lactate levels, which indicated resolving sepsis (median final lactate $1.8 \mathrm{mmol} / \mathrm{L}$ ). The Kaplan-Meier curve for BNP as a predictor for in-hospital mortality showed that for the first 25 days, patients with a BNP greater than $500 \mathrm{pg} / \mathrm{mL}$ had a higher mortality than patients with BNP less than $500 \mathrm{pg} / \mathrm{mL}$ (Fig. 1). However, there was no statistically significant difference in risk of mortality for patients with high against low BNP, either before $(\mathrm{RR}=1.2,95 \%$ confidence interval (CI): 0.9 - 1.6) or after EF and GFR (RR $=1.0,95 \%$ CI: 0.7 - 1.5) adjustment. Also, there was no difference in ICULOS between patients with a higher BNP level compared to those with a lower BNP level either before (IRR = 1.1, 95\% CI: 0.9 - 1.5) or after EF and GFR (RR $=1.1,95 \% \mathrm{CI}$ : 0.8 - 1.4) adjustment. For HLOS, before adjusting for EF and GFR, patients with a higher BNP stayed 21\% longer than those with a lower $\mathrm{BNP}(\mathrm{RR}=1.21,95 \% \mathrm{CI}$ : 1.04 - 1.40), which was attenuated but still significant after adjusting for EF and GFR $(\mathrm{RR}=1.18,95 \% \mathrm{CI}: 1.01-1.39, \mathrm{P}=0.042)$.

\section{Discussion}

We evaluated a cohort of patients who received $3 \mathrm{~L}$ of fluid resuscitation and decreasing lactic acid levels trends. Our study demonstrated a Kaplan-Meier trend for BNP and the risk of mortality in patients with resolving sepsis. Specifically, BNP levels greater than $500 \mathrm{pg} / \mathrm{mL}$ were predictive of hospital mortality within the first 25 days. Our study showed that sepsis mortality was associated with an average of 300 higher BNP units. Additionally, BNP was associated with HLOS. Using these findings, we support the use of BNP as a rapid bedside tool for risk stratifying septic patients.

While the use of BNP has been well studied in the management and prognosis of patients with CHF, coronary syndromes, and pulmonary embolism, its role as a prognostic marker in septic patients is still debatable. Specifically, its role in patients with resolving sepsis has not been assessed prior to our analysis. Apparently, a number of reasons can be accounted for an elevated BNP level in septic patients, including sepsis-induced biventricular dilatation [30], the stimulation of lipopolysaccharide [31], proinflammatory cytokines [8],

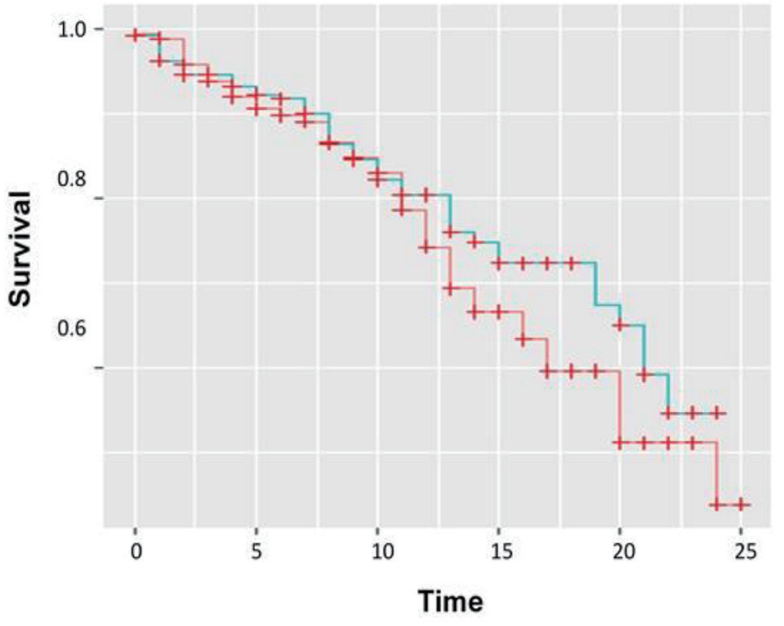

Figure 1. Kaplan-Meier curve showing BNP plotted over time (days) versus survival or mortality. Red: low BNP; blue: high BNP.

impaired renal clearance [32], volume resuscitation [33], and sepsis-associated acute lung injury or ARDS [25].

Several studies have been attempted to establish if BNP or its precursor Pro-BNP are significantly associated with an increased risk of mortality. In a meta-analysis involving a total of 1,865 patients, both inactive and active forms natriuretic peptide were elevated and significantly associated with increased risk of mortality, with a sensitivity and specificity of $79 \%$ and $60 \%$, respectively [7]. Another study involving 254 patients showed that NT-proBNP was an independent predictor of mortality within the first $7 \mathrm{~h}$ after admission [34]. In addition, Guaricci et al (2015) showed that NT-proBNP changes within $72 \mathrm{~h}$ could predict mortality at 28 days in patients with septic shock. The study also found that levels greater than $1,000 \mathrm{pg} /$ $\mathrm{mL}$ at $72 \mathrm{~h}$ were associated with an adverse outcome, sensitivity and specificity of $95.5 \%$ and $94.4 \%$, respectively [4]. Our study did not investigate the predictive value of the inactive forms of BNP.

Serial BNP level might be a useful aide in the early detection, stratification, and management of high-risk septic patients. Chen and Li (2009), and Post et al (2008) have discussed the prognostic value when BNP is used as an adjunct to severity scales such as acute physiology and chronic health evaluation (APACHE) II and sequential organ failure assessment (SOFA) scores. They report that by combining BNP with severity scores, the cumulative result may yield greater prognostic information, and hence facilitate decision making for clinicians and families [23, 35]. However, a review of the literature shows variations in the optimal cut-off point of BNP, ranging from 32.1 to $681.4 \mathrm{pg} / \mathrm{mL}[23,35-41]$. Additionally, it is unclear if some of these studies accounted for initial fluid resuscitation or sepsis resolution.

Elevated BNP indicates that patients stayed longer in hospital and ICU settings. While there are only a few published articles which have investigated this association, our study supports these findings. Zhang et al (2012) reported that a BNP greater than $100 \mathrm{pg} / \mathrm{mL}$ was predictive of ICULOS $>7$ days, and HLOS $>12$ days [42]. Zhao et al (2009) also showed 
that the ICULOS was significantly higher in the BNP elevated cohort compared to the BNP normal group (23.7 \pm 7.5 days vs. $14.9 \pm 5.1$ days, $\mathrm{P}<0.05$ ) [37]. Our study reported that patients with a high BNP had 1.18 times longer average hospital stay. A potential relationship was observed for ICULOS but was diminished after adjusting for EF and GFR. Similarly, while our study did not show any statistical significance correlating BNP and mortality, the Kaplan-Meier curve does indicate a trend which should be evaluated in a larger cohort.

Renal disease and plasma BNP share an inverse relationship. In fact, GFR is inversely related to BNP concentration [32]. This effect is also observed for the inactive forms of BNP. Therefore, the clinical values of BNP differ in patients with renal insufficiency and those with normal renal function. To our best knowledge, there are no clinical guidelines for correcting BNP in the setting of renal insufficiency. As a result, the use of BNP as a biomarker should be taken within the appropriate clinical context.

\section{Conclusion}

Our study demonstrates that BNP could be a powerful tool that can be used to predict mortality in patients with resolving sepsis. We have also shown that BNP level can also aid in determining HLOS and ICULOS. Thus, the clinical value of BNP can facilitate discussions with patient prognosis, decisions regarding interventions, and continuity of care. While this test is inexpensive, rapid, and widely available, further research with larger sample sizes is warranted to clarify the optimal cutoff point in the context of both renal insufficiency and normal functioning kidneys.

\section{Author Contributions}

HS, HP, and GWH participated in the conception and design of the study. MI, SS, RR, and JP participated in data acquisition and analysis. DR and HS interpreted data and drafted the manuscript. HWG revised the manuscript for important intellectual content. All authors gave their final approval prior to submission.

\section{Conflict of Interest}

None.

\section{References}

1. Levin ER, Gardner DG, Samson WK. Natriuretic peptides. N Engl J Med. 1998;339(5):321-328.

2. Nakao K, Ogawa Y, Suga S, Imura H. Molecular biology and biochemistry of the natriuretic peptide system. I: Natriuretic peptides. J Hypertens. 1992;10(9):907-912.

3. Papanikolaou J, Makris D, Mpaka M, Palli E, Zygoulis P, Zakynthinos E. New insights into the mechanisms in- volved in B-type natriuretic peptide elevation and its prognostic value in septic patients. Crit Care. 2014;18(3):R94.

4. Guaricci AI, Santoro F, Paoletti Perini A, Ioffredo L, Trivedi C, Pontone G, Di Biase M, et al. Correlations between NT-proBNP, outcome and haemodynamics in patients with septic shock. Acta Cardiol. 2015;70(5):545552.

5. De Gennaro L, Brunetti ND, Bungaro R, Montrone D, Cuculo A, Pellegrino PL, Correale M, et al. Carbohydrate antigen-125: additional accuracy in identifying patients at risk of acute heart failure in acute coronary syndrome. Coron Artery Dis. 2009;20(4):274-280.

6. Pieralli F, Olivotto I, Vanni S, Conti A, Camaiti A, Targioni $\mathrm{G}$, Grifoni S, et al. Usefulness of bedside testing for brain natriuretic peptide to identify right ventricular dysfunction and outcome in normotensive patients with acute pulmonary embolism. Am J Cardiol. 2006;97(9):13861390.

7. Wang F, Wu Y, Tang L, Zhu W, Chen F, Xu T, Bo L, et al. Brain natriuretic peptide for prediction of mortality in patients with sepsis: a systematic review and meta-analysis. Crit Care. 2012;16(3):R74.

8. He Q, LaPointe MC. Interleukin-1beta regulation of the human brain natriuretic peptide promoter involves Ras-, Rac-, and p38 kinase-dependent pathways in cardiac myocytes. Hypertension. 1999;33(1 Pt 2):283-289.

9. Santos-Araujo C, Leite-Moreira A, Pestana M. Clinical value of natriuretic peptides in chronic kidney disease. Nefrologia. 2015;35(3):227-233.

10. Alberti C, Brun-Buisson C, Burchardi H, Martin C, Goodman S, Artigas A, Sicignano A, et al. Epidemiology of sepsis and infection in ICU patients from an international multicentre cohort study. Intensive Care Med. 2002;28(2):108-121.

11. Biron BM, Ayala A, Lomas-Neira JL. Biomarkers for sepsis: what is and what might be? Biomark Insights. 2015;10(Suppl 4):7-17.

12. Gullo A, Bianco N, Berlot G. Management of severe sepsis and septic shock: challenges and recommendations. Crit Care Clin. 2006;22(3):489-501, ix.

13. Hotchkiss RS, Karl IE. The pathophysiology and treatment of sepsis. N Engl J Med. 2003;348(2):138-150.

14. Martin GS, Mannino DM, Eaton S, Moss M. The epidemiology of sepsis in the United States from 1979 through 2000. N Engl J Med. 2003;348(16):1546-1554.

15. Reinhart K, Bauer M, Riedemann NC, Hartog CS. New approaches to sepsis: molecular diagnostics and biomarkers. Clin Microbiol Rev. 2012;25(4):609-634.

16. Shaw AC. Serum C-reactive protein and neopterin concentrations in patients with viral or bacterial infection. J Clin Pathol. 1991;44(7):596-599.

17. Tschaikowsky K, Hedwig-Geissing $\mathrm{M}$, Braun GG, Radespiel-Troeger M. Predictive value of procalcitonin, interleukin-6, and C-reactive protein for survival in postoperative patients with severe sepsis. J Crit Care. 2011;26(1):54-64.

18. Maruna P, Nedelnikova K, Gurlich R. Physiology and genetics of procalcitonin. Physiol Res. 2000;49(Suppl 1):S57-61. 
19. Sridharan P, Chamberlain RS. The efficacy of procalcitonin as a biomarker in the management of sepsis: slaying dragons or tilting at windmills? Surg Infect (Larchmt). 2013;14(6):489-511.

20. Garnacho-Montero J, Huici-Moreno MJ, GutierrezPizarraya A, Lopez I, Marquez-Vacaro JA, Macher H, Guerrero JM, et al. Prognostic and diagnostic value of eosinopenia, C-reactive protein, procalcitonin, and circulating cell-free DNA in critically ill patients admitted with suspicion of sepsis. Crit Care. 2014;18(3):R116.

21. de Jager CP, van Wijk PT, Mathoera RB, de Jongh-Leuvenink J, van der Poll T, Wever PC. Lymphocytopenia and neutrophil-lymphocyte count ratio predict bacteremia better than conventional infection markers in an emergency care unit. Crit Care. 2010;14(5):R192.

22. Witthaut R, Busch C, Fraunberger P, Walli A, Seidel D, Pilz G, Stuttmann R, et al. Plasma atrial natriuretic peptide and brain natriuretic peptide are increased in septic shock: impact of interleukin-6 and sepsis-associated left ventricular dysfunction. Intensive Care Med. 2003;29(10):1696-1702.

23. Post F, Weilemann LS, Messow CM, Sinning C, Munzel T. B-type natriuretic peptide as a marker for sepsisinduced myocardial depression in intensive care patients. Crit Care Med. 2008;36(11):3030-3037.

24. Pirracchio R, Deye N, Lukaszewicz AC, Mebazaa A, Cholley B, Mateo J, Megarbane B, et al. Impaired plasma B-type natriuretic peptide clearance in human septic shock. Crit Care Med. 2008;36(9):2542-2546.

25. Forfia PR, Watkins SP, Rame JE, Stewart KJ, Shapiro EP. Relationship between B-type natriuretic peptides and pulmonary capillary wedge pressure in the intensive care unit. J Am Coll Cardiol. 2005;45(10):1667-1671.

26. Maeder M, Fehr T, Rickli H, Ammann P. Sepsis-associated myocardial dysfunction: diagnostic and prognostic impact of cardiac troponins and natriuretic peptides. Chest. 2006;129(5):1349-1366.

27. Cockcroft DW, Gault MH. Prediction of creatinine clearance from serum creatinine. Nephron. 1976;16(1):31-41.

28. Strunk A, Bhalla V, Clopton P, Nowak RM, McCord J, Hollander JE, Duc P, et al. Impact of the history of congestive heart failure on the utility of B-type natriuretic peptide in the emergency diagnosis of heart failure: results from the Breathing Not Properly Multinational Study. Am J Med. 2006;119(1):69 e61-11.

29. Brenden CK, Hollander JE, Guss D, McCullough PA, Nowak R, Green G, Saltzberg M, et al. Gray zone BNP levels in heart failure patients in the emergency department: results from the Rapid Emergency Department Heart Failure Outpatient Trial (REDHOT) multicenter study. Am Heart J. 2006;151(5):1006-1011.
30. Court O, Kumar A, Parrillo JE. Clinical review: Myocardial depression in sepsis and septic shock. Crit Care. 2002;6(6):500-508.

31. Tomaru Ki K, Arai M, Yokoyama T, Aihara Y, Sekiguchi Ki K, Tanaka T, Nagai R, et al. Transcriptional activation of the BNP gene by lipopolysaccharide is mediated through GATA elements in neonatal rat cardiac myocytes. J Mol Cell Cardiol. 2002;34(6):649-659.

32. Takase H, Dohi Y. Kidney function crucially affects Btype natriuretic peptide (BNP), N-terminal proBNP and their relationship. Eur J Clin Invest. 2014;44(3):303-308.

33. Phua J, Lim TK, Lee KH. B-type natriuretic peptide: issues for the intensivist and pulmonologist. Crit Care Med. 2005;33(9):2094-2013.

34. Varpula M, Pulkki K, Karlsson S, Ruokonen E, Pettila V. Predictive value of N-terminal pro-brain natriuretic peptide in severe sepsis and septic shock. Crit Care Med. 2007;35(5):1277-1283.

35. Chen Y, Li C. Prognostic significance of brain natriuretic peptide obtained in the ED in patients with SIRS or sepsis. Am J Emerg Med. 2009;27(6):701-706.

36. Perman SM, Chang AM, Hollander JE, Gaieski DF, Trzeciak S, Birkhahn R, Otero R, et al. Relationship between B-type natriuretic peptide and adverse outcome in patients with clinical evidence of sepsis presenting to the emergency department. Acad Emerg Med. 2011;18(2):219-222.

37. Zhao HY, An YZ, Liu F. [Prognostic values of B-type natriuretic peptide in severe sepsis and septic shock]. Zhongguo Wei Zhong Bing Ji Jiu Yi Xue. 2009;21(5):293295.

38. Yucel T, Memis D, Karamanlioglu B, Sut N, Yuksel M. The prognostic value of atrial and brain natriuretic peptides, troponin I and C-reactive protein in patients with sepsis. Exp Clin Cardiol. 2008;13(4):183-188.

39. Ueda S, Nishio K, Akai Y, Fukushima H, Ueyama T, Kawai Y, Masui K, et al. Prognostic value of increased plasma levels of brain natriuretic peptide in patients with septic shock. Shock. 2006;26(2):134-139.

40. Charpentier J, Luyt CE, Fulla Y, Vinsonneau C, Cariou A, Grabar S, Dhainaut JF, et al. Brain natriuretic peptide: A marker of myocardial dysfunction and prognosis during severe sepsis. Crit Care Med. 2004;32(3):660-665.

41. Sturgess DJ, Marwick TH, Joyce C, Jenkins C, Jones M, Masci P, Stewart D, et al. Prediction of hospital outcome in septic shock: a prospective comparison of tissue Doppler and cardiac biomarkers. Crit Care. 2010;14(2):R44.

42. Zhang Z, Xue Y, Xu X, Ni H. Prognostic value of B-type natriuretic peptide (BNP) and its potential role in guiding fluid therapy in critically ill septic patients. Scand J Trauma Resusc Emerg Med. 2012;20:86. 